social care professionals. Three rated their overall experience as excellent and one as very good.

Conclusions There was excellent engagement from the care homes who participated in Project $\mathrm{ECHO}^{\mathrm{TM}}$. This was reflected in the very positive feedback that included many examples of changes in practice since participating. There was good evidence of two-way learning between care homes, and between care homes and hospice staff. This network has continued and another two care homes have since joined.

\section{P-62 PROJECT ECHOTM: DEVELOPING A MULTI- PROFESSIONAL VIRTUAL COMMUNITY OF PRACTICE FOR PARAMEDICS IN END OF LIFE CARE}

${ }^{1}$ Andrew Hodge, ${ }^{2}$ Laura McTague, ${ }^{2}$ Jane Manson, ${ }^{2}$ Paul Taylor. ' Yorkshire Ambulance Service NHS Trust, Wakefield, UK; ${ }^{2}$ St Luke's Hospice, Sheffield, UK

\subsection{6/bmjspcare-2019-HUKNC.86}

Background Paramedics report unique challenges delivering end of life care, including accessing education and low confidence (Pettifer \& Bronnert, 2018). NHS Ambulance Services cover large geographical areas and education is typically centralised.

Project $\mathrm{ECHO}^{\mathrm{TM}}$ (Extension of Community Healthcare Outcomes) utilises a tele-mentoring network to develop virtual communities of practice to enable case-based learning to manage complexity across geographically challenged services.

Prior Project $\mathrm{ECHO}^{\mathrm{TM}}$ implementations have demonstrated improved competence, confidence and patient related health outcomes (Arora, Kalishman, Thornton, Dion et al., 2010; Zhou, Crawford, Serhal, Kurdyak et al., 2016).

Aim To develop and deliver an effective end of life care training and education programme for paramedics using $\mathrm{ECHO}^{\mathrm{TM}}$ methodology.

Methods A virtual approach was utilised to support participant engagement, recruitment, knowledge events, $\mathrm{ECHO}^{\mathrm{TM}}$ sessions and evaluation. Two programmes of five sessions, occurring monthly were facilitated by a Consultant Palliative Physician and Consultant Paramedic. Participants 'dialled in' remotely using Zoom. Each session comprised an expert talk and two anonymised case presentations from participants, forming the basis for facilitated discussions.

Electronic surveys based on end of life care and paramedic research (Smith, Arnold, Kinghorn, Poppleton, 2010) were: a knowledge questionnaire on recruitment; self-completed training needs analysis of competence and confidence at the start, midpoint and end, and individual session evaluations for session quality and fidelity to the model.

Results Programme 1:

- Statistically significant improvements $(p>0.05)$ in selfreported competence and confidence across all five sessions and end of life care competencies;

- Attendance ranged from 60-93\%;

- Potential travel cost savings were $£ 2215.08$ (4922.4 miles);

- Development of a multi-professional virtual community of practice: paramedics, physiotherapists, occupational therapists, consultants and GPs understanding each other's roles and challenges;
- No major IT access, sound or vision problems identified and participants highly rated $\mathrm{ECHO}^{\mathrm{TM}}$ session delivery by the hub team.

Programme 2: results under analysis.

Conclusions Attendance and recruitment rates indicate that $\mathrm{ECHO}^{\mathrm{TM}}$ is an accessible model of education delivery. A multiprofessional virtual community of practice was developed. Survey findings support the successful application of this model to paramedics delivering end of life care, resulting in statistically significant improvements in self-reported competence and confidence.

\section{P-63 PROJECT ECHOTM NI \& HOSPICE UK: A TEAM APPROACH -INGREDIENTS REQUIRED!}

${ }^{1}$ Aine McMullan, ${ }^{2}$ Tracey McTernaghan. 'Health and Social Care Board, Belfast, UK; ${ }^{2}$ Hospice UK, Belfast, UK

\subsection{6/bmjspcare-2019-HUKNC.87}

Background Project $\mathrm{ECHO}^{\mathrm{TM}}$ (Extension for Community Healthcare Outcomes) is a tele-mentoring programme that uses video-conferencing technology to share evidence-based knowledge, best practice and education by using case-based learning.

From 2017 Hospice UK is commissioned by the Health and Social Care Board in Northern Ireland to deliver 30 Project $\mathrm{ECHO}^{\mathrm{rm}}$ networks. The vision is to engage with health and social care professionals to develop their knowledge base and skills, transforming service delivery and ultimately the care given to the people of Northern Ireland.

As a collaborative partnership the Project Managers are tasked with implementing the operational delivery of the project. They considered that a vital ingredient for success would be to connect the team with a sense of higher purpose. This strategic driver should inspire a team to bring increased commitment, energy and creativity to their job. A higher purpose shows team members how they are making a difference, giving each within their role a sense of meaning and drawing their support to deliver the project.

Aim To establish components of a newly appointed Project $\mathrm{ECHO}^{\mathrm{TM}}$ team to operationally deliver the programme.

Method Weekly team meetings and monthly meetings with directors and project managers to track the progress of the project programme. In addition, a team review day after the seven months to review the vision of the project, roles and responsibilities of the team.

Results Project Managers established the following components after the successful delivery of the programme in year 1 :

- Clearly defined roles;

- Induction programmes;

- Clear communication channels;

- Office environment;

- Supportive learning environment;

- Team meetings.

Conclusions A strategic recognition that a sense of higher purpose is not about economic exchanges, that working together for a 'greater good' reflects something more aspirational to a team approach. 